\title{
Virtual environments for safety learning in construction and engineering: seeking evidence and identifying gaps for future research
}

\author{
Mohamad Kassem¹, Leila Benomran² and Jochen Teizer ${ }^{3^{*}}$
}

\begin{abstract}
Background: Injuries and fatalities resulting from work place accidents remain a global concern within the construction and engineering sectors. Education and training of personnel are two of the primary approaches for establishing a safe work environment. Virtual Environments (VE) are being increasingly investigated as a complementary approach for safety learning. Despite the proliferation of VE studies for safety learning, there is still limited evidence about their effectiveness or benefits, extent of coverage of the risk management process, and limitations.

Methods: This articles poses the following research questions: (1) are VE providing an effective learning means to address safety risks in construction and engineering sectors?, (2) what are the areas that require improvement?, and (3) to what extent are $\mathrm{VE}$ addressing the established risk management process (i.e., risk identification, risk evaluation, risk response planning, and risk monitoring and control)? To address these the research questions, this research employs: (a) a systematic literature review and analysis of VE studies for safety learning; and (b) a gap analysis technique.

Results: The findings suggest: (a) the evidence of the effectiveness of VE as an intervention for safety learning across the entirety of the risk management process are still limited; (b) 'risk identification', where learners improve their abilities to spot hazards, is the most investigated phase in the risk management process, (c) VE applications in other risk management phases (i.e. 'risk evaluation', 'risk response planning', and 'risk monitoring and controlling') receive very limited attention compared to the risk identification phase.

Conclusion: The areas of recommendations for future research included the need to: (a) intensify real-life observational studies to provide evidence about the comparative performance of learners in VE against those of learners by other means through the setting of control groups; (b) extend studies to, and concurrently address, all the risk management phases; (b) intensify studies in other sectors including chemical, oil and gas, and manufacturing; (d) address human factors such as communication, language and cognitive distraction. An analysis of the limitations of current VE studies in each of the recommendation areas accompanied with suggestions for future research is proposed.
\end{abstract}

Keywords: Augmented reality, Cognitive skills, Construction safety, Engineering industry, Human behavior, Risk management, Virtual environment, Virtual reality, Workforce education and training

\footnotetext{
* Correspondence: jochen.teizer@rub.de

${ }^{3}$ Chair of Computing in Engineering, Ruhr-University Bochum, Bochum,

Germany

Full list of author information is available at the end of the article
} 


\section{Introduction}

Workforce safety is a global concern. The engineering industry, in particular the construction sector, has one of the highest rates in fatal injuries (Table 1). For example, construction in the United Kingdom (UK) is regarded as one of the most hazardous industries: $32 \%$ of all UK fatalities occur in construction despite the sector's employment of $6.3 \%$ of the total workforce (HSE 2015b). Recent statistics from other countries (see Table 1) show that the reported fatalities in the construction industry remain very high.

This is a reason, why improving the safety performance in the construction and wider engineering industry has attracted significant interest recently. Multiple methods of interventions have been investigated including the use of Virtual Environments (VE) to train and educate students and industry workers on safety management. Although full scientific corroboration and mature practical solutions are yet to be reached, three key propositions underpin research and development in VE:

- there is a link between the rehearsed activities and performance within the VE and the actual performance and learning outcomes (Bachvarova et al. 2012; Li et al. 2008; Lin et al. 2011),

- training in VE reduces the time and cost compared to the learning and training process in the real world (Bachvarova et al. 2012; Li et al. 2008; Lin et al. 2011), and

- VE provide the possibility of conducting training on high risk activities that cannot be implemented in field-based training (Addison et al. 2013), for example, the feasibility of setting hazardous situations that endangers a person's life (Liu et al. 2010).

While the second and third propositions can be reasonably accepted without the need for research exploration, it is important to corroborate research evidence about the first proposition. Indeed, if the third proposition is not valid, the benefit of VE expressed in the first two propositions would become insignificant for the purpose of safety learning and training. Unless such evidence is provided about the link between VE learning and training and the actual performance outcomes of learners, research in this area would merely be based on anecdotal evidence. Using these considerations as a point of departure, this paper aims to address two key research questions:

- are VE providing an effective learning and training means to address safety risks in construction and engineering industry?; and

- to what extent VE are addressing the established risk management process (i.e., risk identification, risk evaluation, risk response planning, and risk monitoring and control).

To address the two research questions, this paper reviews and analyses the body of the literature proposing VE as an intervention to address safety risks in the engineering sector. This includes, as far as the selected scientific databases cover them, sectors in the construction, military, manufacturing, oil and gas and other related engineering sectors. The study adopts a protocol-led systematic literature review and a gap analysis technique based on a proven risk management process (ISO 31000-2009) (ISO 2009). It seeks to determine whether there is evidence about the uses and benefits of VE for addressing safety risks in the construction and engineering industry. It will identify potential research gaps and future directions.

The identified studies in the systematic review will be mapped against the risk management framework. Potential gaps will be identified and recommendations will be made. The following sections provide: (a) clarification of the terms used across the reviewed research articles; (b) explanation of the methodology and stages used in the research; (c) analysis of the identified studies according to their coverage of the risk management process, learner groups and countries; (d) discussion of the communalities, differences and gaps in the identified studies, and (e) suggestion of recommendations for future research, and (f) conclusions.

\section{Review of key terms and concepts}

The 'Construction and Engineering Industry' incorporates all economic sectors or activities that are involved in the realization of physical assets. It encompasses all technical sectors that are characterized with complex processes and systems. These include the building, civil, chemical, and oil and gas sectors.

Table 1 Recent construction workforce safety statistics from China, Germany, UK, and U.S.

\begin{tabular}{ll}
\hline Country & Fatalities \\
\hline China & 2634 construction workers lost their lives in 2011 (State Administration for Work Safety 2013) \\
Germany & 86 fatalities in construction in 2015. An average of 91 lives per year between 2010 and 2015 (Teizer and Melzner 2015) \\
UK & 144 fatal injuries in 2016, of which 43 were recorded in the construction industry (same as the 5-year average of 43) (HSE 2016) \\
U.S. & 937 construction fatalities recorded in 2015 (OSHA 2017) \\
\hline
\end{tabular}


'Virtual Environments' (VE) are acknowledged as computer-based virtual machine settings, which are a combination of virtual machine monitors and hardware platforms (Hale and Stanney 2014). In this paper, VE will be considered as inclusive of all forms of visualization including Virtual Reality, Serious Games and 'Building Information Modelling'-based applications such as ' $4 D$ ' (three-dimensional model and project schedule). Example applications related to BIM are shown in Figs. 1 and 2.

'Virtual Reality' (VR) engages not only the user's vision but also the sound, haptic (touch), smell and taste with computer interfaces that encompass often real-time interaction (Burdea and Coiffet 2003). The concept of VR was first materialized in the 1950's and has rapidly developed in many fields for a multitude of purposes (Mihelj et al. 2013). Key applications of VR are in the education and training as it represents a safe and controlled environment for learning purposes. Much of these VR applications are implemented through the use of a game for learning or training purposes which can be considered as a 'Serious Game' (Navarro 2012). The term 'Serious Game' is based on the notion that a connection is formed between a serious purpose - other than fun -, information and gaming technology (Sawyer and Rejeski 2002). Serious games do not place amusement as the primary objective (Chen and Michael 2005) and must be able to contextualize the user experience in realistic stimulating environments which encourage situational learning (Watkins et al. 1998).

Using the above definitions of VE and VR, studies were included in the review even if they address only the user's vision. Other forms of VE are those associated with Building Information Modelling (BIM) environments. BIM is considered as the current expression of digital innovation within the construction industry (Succar and Kassem 2015) and its emerging uses are being explored in all areas of the construction sector including the safety education and training (Zhang et al. 2014). 4D refers to a virtual and visual rehearsal of the construction schedule obtained by adding the time to the model objects.

Safety risks are managed according to a proven risk management framework (ISO 31000-2009) which is universally adopted across all industry sectors (ISO 2009). The Risk Management Process includes four key phases, namely of risk identification, risk evaluation, risk response planning, and risk monitoring and controlling. They are implemented throughout the lifecycle of any project to either eliminate or reduce the impact or probability of any adverse event.

Risk identification is the first step in the management process and aims to capture and record all potential causes of hazards. Risk evaluation entails assessing the magnitude of each risk based on its probability of occurrence and impact. This can be achieved using qualitative or quantities methods. The aim of the risk evaluation phase is to prioritize the risks separating the acceptable ones from those that will require treatment (HSE 2015a). The results from the risk evaluation are then used to develop adequate measures at the risk response planning. In setting up responses to the evaluated risks, the response strategy usually employs a sequential hierarchy of measures that starts with eliminating the risk as a first priority, with the subsequent steps being to reduce, isolate, control, and implement safe systems of work or as a last resort employ the use of Personal Protective Equipment (PPE) (Butler 2014). The risk monitoring and
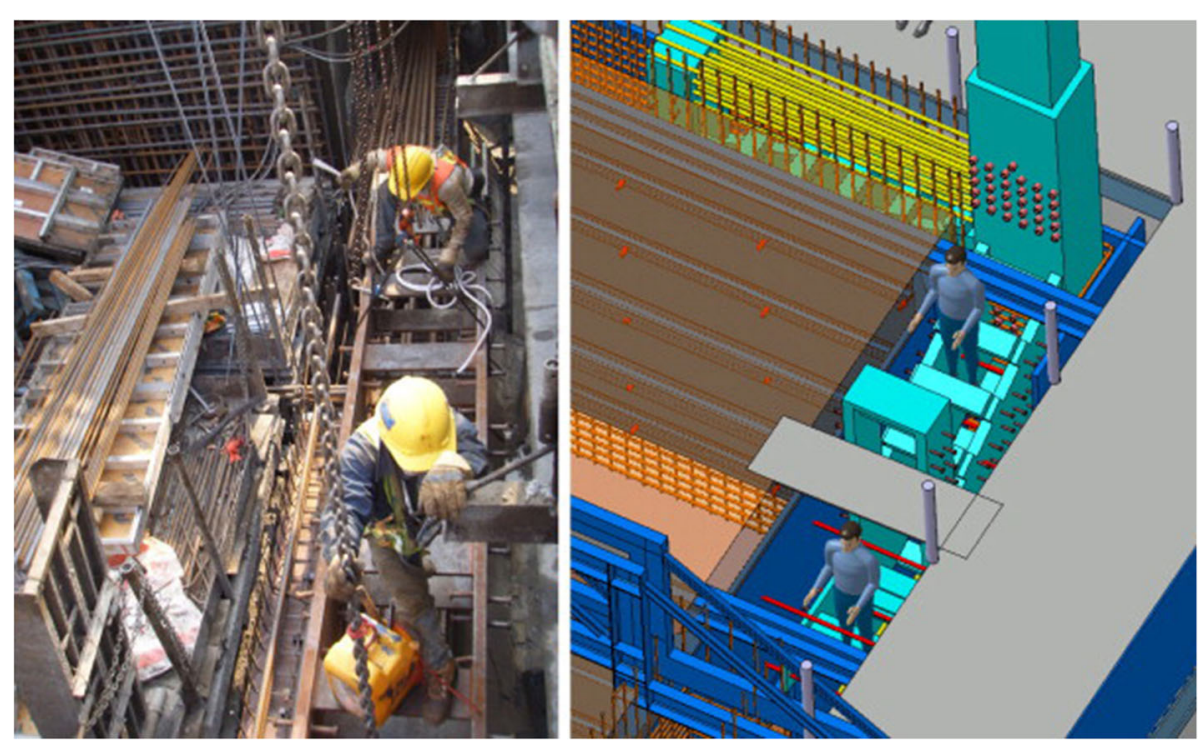

Fig. 1 Visualizing confined workspace (Li et al. 2008) 


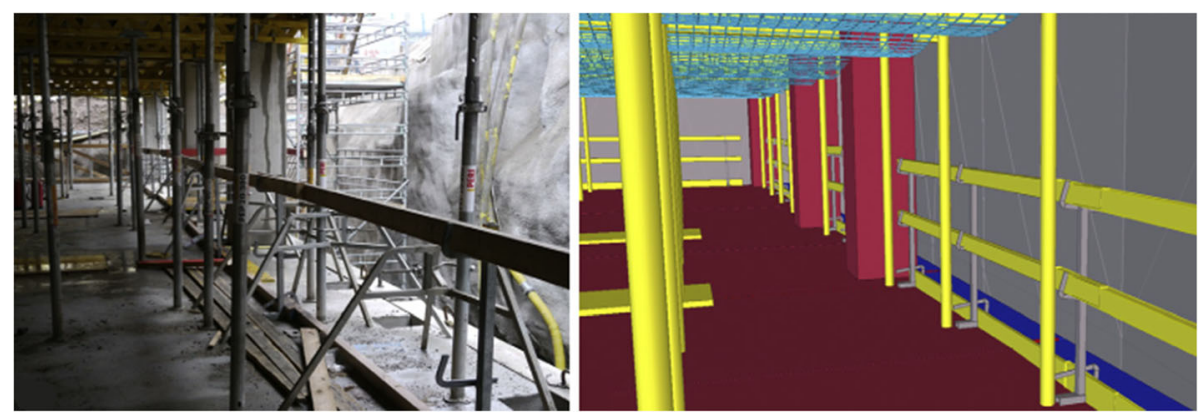

Fig. 2 Planning protective guardrails (Teizer and Melzner 2015)

controlling phase implements either proactive routine inspections or reactive examination after an incident has occurred. It aims to ensure the effectiveness of the implemented risk management measures. In combination, the phases of risk management provide a proven approach for risk prevention and reduction. Therefore, managing safety risks in the engineering industry requires knowledge and skills in the implementation of all the phases of the risk management process. It is expected that VE research studies for safety education and training address the needs of this process by covering all its core three phases (risk identification, risk evaluation, risk response planning). This paper also verifies this hypothesis by mapping the identified studies against the key phases of the risk management process.

\section{Methodology: stages and implementation}

The methodology adopted in this research combines a systematic literature review and a gap analysis technique. The systematic literature review is usually used to identify and assess available studies on a topic area or a focused research question. It aims to present a fair evaluation of a research topic by using a trustworthy, rigorous, and auditable methodology (Kitchenham and Charters 2007). It follows a transparent process with a predefined search strategy (Boland 2014).

An essential step in systematic literature reviews is to develop a focused research aim to ensure that the search is directed towards relevant literature (Aveyard 2010). For this paper, the aim was developed by adapting the structural outline of PICO (Population, Intervention, Comparison, and Outcome) (Table 2). By joining the different elements of the PICO structure, the research aim was formulated as 'review and analysis of virtual environment research as an intervention to address the construction and engineering industry safety risks through educating and training. This element in the design of the systematic literature review is crucial to both (1) direct the search towards paper contributing to our quest for evidence regarding the effectiveness of $\mathrm{VE}$ as intervention for to address safety risks within the construction and engineering industry, and (2) exclude VE studies for safety learning and training that do not include that element of evidence or comparative performance.

Following the setting of the research focus, the next step is to define an adequate search strategy. The search strategy, if applied properly within a systematic literature review, can lead to representative results with limited or irrelevant exclusions (Hamer and Collinson 2005). The search strategy included the following stages and outcomes:

\section{- Stage 0 - Identifying pertinent databases and} defining keywords and Boolean operators:

Electronic databases pertinent to education, social sciences, engineering and information technology were selected. SCOPUS was the main search portal utilized as it hosts a multi-disciplinary research platform, holding a wide selection of peer-reviewed journals. Individual databases searched were: ScienceDirect, ASSIA (Applied Social Science Index and Abstract), ACM (Association for Computer Machinery), and ITCon (Information Technology in Construction). The research question must be divided into keywords for the purpose of searching the databases (Petticrew and Roberts 2008). Table 3 shows the PICO structure and Boolean operators that were used to aid breaking the research question down into its components and keywords. Other well suitable keywords exist, for example 'military' or

Table 2 The PICO structure for the proposed research

\begin{tabular}{ll}
\hline P: Population & $\begin{array}{l}\text { Construction and Engineering industry } \\
\text { Workforce }\end{array}$ \\
$\begin{array}{l}\text { I: Intervention or issue } \\
\text { of interest }\end{array}$ & VE to improve safety learning and training \\
C: Comparison & $\begin{array}{l}\text { Comparison of performance between } \\
\text { learners in VE vs. learners by other means } \\
\text { O: Outcome }\end{array}$ \\
& $\begin{array}{l}\text { Improved health and safety performance } \\
\text { of workforce? }\end{array}$ \\
\hline
\end{tabular}


Table 3 Keywords and Boolean logic used in the search strategy

\begin{tabular}{|c|c|c|}
\hline Strand & $\mathrm{PICO}$ & Keywords \\
\hline \multirow[t]{5}{*}{ S1 } & \multirow[t]{5}{*}{ Population } & Engineering Industry OR \\
\hline & & Construction OR \\
\hline & & Oil \& Gas OR \\
\hline & & Mechanical OR \\
\hline & & Chemical \\
\hline \multirow[t]{5}{*}{ S2 } & \multirow[t]{5}{*}{ Intervention } & Virtual Reality OR \\
\hline & & VR OR \\
\hline & & Visualization OR \\
\hline & & Serious Games OR \\
\hline & & Game Engines \\
\hline \multirow[t]{6}{*}{ S3 } & \multirow[t]{6}{*}{ Comparison } & Performance OR \\
\hline & & Health and Safety OR \\
\hline & & Health and Safety Performance OR \\
\hline & & Risk OR \\
\hline & & Hazard OR \\
\hline & & Threat \\
\hline \multirow[t]{5}{*}{ S4 } & \multirow[t]{5}{*}{ Outcome } & Education OR \\
\hline & & Training OR \\
\hline & & Learning OR \\
\hline & & Teaching OR \\
\hline & & Knowledge \\
\hline
\end{tabular}

'manufacturing' for population and 'virtual environment' and 'augmented reality' for intervention. These can be added in future research.

- Stage 1 - Pilot search: This stage applies the keywords without any specific filters. It is an important stage in the process to identify all of the potential primary studies on the topic (Kitchenham and Charters 2007). This pilot search examined all aforementioned databases and returned more than 30 thousands results suggesting a significant interest in the search terms.

- Stage 2 - Amended search: In this stage the initial search is amended to exclude the studies that are not relevant to the research question by applying the Boolean and other filters and limits. Due to the high volume of literature retrieved in the trial search, limitations were applied to restrict studies outside of the years ranging from 2000 to 2015 (in total 16 years). All book chapters were omitted and marked as an exclusion filter. Amendments also included developing a filter using the 'NOT' Boolean operator to exclude papers that were of a medical nature. The amended search strategy returned 331 papers.

- Stage 3 - Title and abstract search: This stage examines the titles and abstract of the papers returned from Stage 2 and exclude studies that are not relevant to the research question: titles that did not mention virtual environment/reality/ visualization or training terms were excluded; abstracts that did not mention the construction and engineering industry terms, and studies that did not include assessment and/or comparison of safety performance, were all excluded at this stage. At the end of this stage 243 papers were excluded and 88 passed to the second stage.

- Stage 4 - Inclusion/exclusion criteria: This stage applied the inclusion and exclusion criteria from Table 4. The papers excluded at this stage were mainly studies that were not fully focused on safety and/or did not include evaluation or case studies of the VE with the involvement of learners. 39 studies remained at the end of this stage.

\section{- Stage 5 - Methodological assessment for final} inclusion: This stage assesses the full text of the identified studies and judges their methodological quality. The results were compiled for all studies in a methodological quality standard assessment check sheets. The papers were assessed based on the structure and quality of the introduction, research method, results and conclusion. 11 studies were excluded at this stage and 28 studies represented the final seed of studies.

- Stage 6 - Final inclusion of papers and coding: The identified 28 studies were collated in a master table, which in addition to their general metadata (author, year of publication, title of study) included their key characteristics (type of learners/ participants, engineering sector type, risk management phase/skill) was created to clearly display the results. Table 5 includes a brief summary of the identified studies and their major contributions.

Table 4 Inclusion and exclusion criteria

\begin{tabular}{ll}
\hline Inclusion criteria & Exclusion criteria \\
\hline - Primary studies that are related & - Studies that do not cover the \\
to the research aim & specific themes of the research \\
- Studies of high methodological & aim \\
standards & - Material that is not based in \\
- Academic or peer-reviewed journals & the specified setting of the \\
- Material written in English language & engineering industry and \\
- Studies that include the testing of & health and safety education \\
the VE in with the involvement of & and training \\
learner groups & - Studies that do not include \\
& evaluation or testing of the \\
& VE with the involvement \\
& of learners \\
& - Material that is duplicated \\
& - Studies in languages other \\
& than English \\
\hline
\end{tabular}


Table 5 Studies identified from the application of the systematic literature review's search strategy and protocols

\begin{tabular}{|c|c|}
\hline Author & Title \\
\hline Carozza et al. (2013) & Image-based localization for an indoor VR/AR construction training system \\
\hline Cheng and Teizer (2013) & $\begin{array}{l}\text { Real-time resource location data collection and immersive 3D visualization technology for construction } \\
\text { safety and activity monitoring applications }\end{array}$ \\
\hline Dawood et al. (2014) & Construction health and safety training: the utilization of $4 \mathrm{D}$ enabled serious games \\
\hline Dickinson et al. (2011) & Game based trench safety education: Development and lessons learned \\
\hline Guo et al. (2012) & VP-based safety management in large-scale construction projects \\
\hline Guo et al. (2013) & Serious game for the safety training of using heavy plant equipment \\
\hline Goulding et al. (2012) & Construction industry offsite production: A virtual reality interactive training environment prototype \\
\hline Greuter et al. (2012) & Designing a game for occupational health and safety in the construction industry \\
\hline Hadikusumo and Rowlinson (2002) & Integration of virtually real construction model and design-for-safety-process database \\
\hline Li et al. (2012a) & Visualizing safety assessment by integrating the use of game technology \\
\hline Li et al. (2012b) & A multi-user virtual safety training system for tower crane dismantlement \\
\hline Li et al. (2015) & Proactive training system for safe and efficient precast installation \\
\hline Lin et al. (2011) & A pilot study of a 3D game environment for construction safety education \\
\hline Nakai et al. (2014) & The experience-based safety training system using VR technology for chemical plant \\
\hline Nazir et al. (2013) & Minimizing the risk in the process industry by using plant simulator: A novel approach \\
\hline Nickel et al. (2013) & A virtual reality pilot study towards elevating work platform \\
\hline Park and Kim (2013) & A framework for construction safety management and visualization \\
\hline Perlman and Sacks (2014) & Hazard recognition and risk perception in construction \\
\hline Sacks et al. (2013) & Construction safety training using immersive virtual reality \\
\hline Teizer et al. (2013) & $\begin{array}{l}\text { Location tracking and data visualization technology to advance construction ironworkers' education } \\
\text { and training in safety and productivity }\end{array}$ \\
\hline Visser et al. (2012) & Reducing the dangers of operator distraction through simulation training \\
\hline Wang and Dunston (2007) & Design, strategies, and issues towards an augmented reality-based construction training platform \\
\hline Wang et al. (2015) & Applying building information modelling to support fire safety management \\
\hline Xie and Carr (2010) & Ultrasonic sensor and 4D virtual reality simulation environment for safety training \\
\hline Xie et al. (2006) & Development of a virtual reality safety-training system for construction workers \\
\hline Zhang et al. (2015) & $\begin{array}{l}\text { Ontology-based semantic modelling of construction safety knowledge: Towards automated safety } \\
\text { planning for job hazard analysis }\end{array}$ \\
\hline Zhang et al. (2013) & $\begin{array}{l}\text { Building Information Modelling (BIM) and safety: automatic safety checking of construction models } \\
\text { and schedules }\end{array}$ \\
\hline Zhou et al. (2013) & Application of 4D visualization technology for safety management in metro construction \\
\hline
\end{tabular}

\section{Overview of the identified studies}

The studies obtained from the systematic literature review proposed a wide range of VE applied for different safety purposes.

Carozza et al. (2013) employs the use of virtual reality goggles to train construction site workers in forming the ability to identify risks. The study authors reported the benefits to be realistic training without any of the associated risks that would occur if the virtual scenarios were to be replicated in a real world setting.

Cheng and Teizer (2013) presented three studies that proposed an approach for blending real-time data and visualization of a construction site in the delivery of a simulated and realistic virtual training environment. The results highlighted that construction information that is related to safety can be automatically monitored leading to improved safety situational awareness of workers or decision makers on any project where real-time tracking and visualization is employed.

Dawood et al. (2014) developed a full scale virtual construction site to test the ability of learners to identify hazards in a virtual environment at different construction phases represented within a serious game. The virtual environment included a combination of hazards with varying levels of difficulty of identification. The results indicated that as construction sites become more complex over time - as construction work progresses the ability of learners to identify hazards decreases. This 
is an indication of the importance of advancing the applications of serious games to complex site situations.

Dickinson et al. (2011) developed a serious game that can be adapted to several safety training scenarios. Risk evaluation was the main focus of the serious game. The testing of the serious games demonstrated that it can offer an engaging and innovative medium for delivering training to students.

Goulding et al. (2012) focuses on the managerial training to assist in enhancing early stage decision making from a manager's perspective. The participants involved in the testing were students who witnessed an improved learning experience and an appreciation of the real life scenarios from a construction manager's perspective.

Guo et al. (2012) highlighted the lack of practical skills by students who wish to enter a career into construction after graduation (Guo et al. 2012). They proposed a game technology-based safety training platform to address this challenge. A case study, in which major construction plant equipment was represented in a virtual environment to train the students and increase their learning experience, showed improvement in student knowledge gaining and retention.

Guo et al. (2013) combined 3D models and process simulations to aid construction workers in the identification of potential hazards on construction sites. In a live case study 2D drawings were used to create a 3D model and simulation to train construction workers in hazard recognition. The results indicated that safety risks can be identified in advance. The live case study resulted in a hazard free site record.

Greuter et al. (2012) hypothesized that serious games assist the learning experience of students in their hazard identification skills before entering into real life construction sites. The serious game created was based on the Australian safety legislation and helped enhance the learning experience and knowledge retention of the participating students.

Hadikusumo and Rowlinson (2002) discussed the components of a design-for-safety-process tool. The mechanisms of the tool are described to be inclusive of virtual reality construction components coupled with construction processes utilizing a design-for-safety-process database (Hadikusumo and Rowlinson 2002). Participants roam the virtually reality system to identify safety hazards and consider the precautions needed to prevent the occurrence of accidents.

Li et al. (2012a) explained that a green card system is required in Hong Kong to access and perform work on a construction site. Workers obtain the green card after passing a test with multiple choice questions $(\mathrm{Li}$ et al. 2012a). However, according to the authors the system has significant pedagogical limitations and does not reflect the complexities and spatial characteristics of the construction site. The authors proposed a virtual assessment system which was tested in a case study with the participation of construction workers, engineers and safety officers. The results of the test indicated that the safety engineers perform better than the general construction workers. Li et al. (2012b) examined the use of a multi-user serious game to train workers in risk identification. The game provided multiple roles available for participants to choose from in order to explore the risks from different perspectives and aimed to simulate the dynamic nature of a construction site. The study participants were split into three groups based on their level of experience. The results showed that the group with no tower crane demobilization experience identified the least number of hazards. These results suggest that prior work experience affect the performance of learners in a virtual environment.

Lin et al. (2011) proposed a serious game in which a group of students assume the role of a safety inspector responsible for identifying safety hazards. The results showed that the students are highly interested in this type of digital learning. Data obtained through a follow up questionnaire indicated that the students are more likely to identify hazards following the training using the serious game.

Nakai et al. (2014) proposed a virtual chemical plant environment where the operator can experience fire and explosion accidents in the virtual space (Nakai et al. 2014). The authors argued that the environment help trainee in learning the correct use of equipment and implementation of processes in order to prevent accidents and reduce human error.

Nazir et al. (2013) presented a study in the oil and gas sector where a plant simulator using immersive virtual reality technology was used to train participants on risk identification and prevention. The results indicated that participants operating the virtual plant simulator are more likely to recognize and prevent risks in real situations.

Nickel et al. (2013) developed a virtual reality tool for training on the risk identification in the operation a mobile elevated work platform. In a pilot study where immersive virtual reality technologies - 3D glasses - were utilized, the results indicated that the participants find the immersion as highly effective in enhancing the overall experience and training scenario.

Park and Kim (2013) designed a safety management visualization system that included a series of questions and answers based on real construction site circumstances and activities. A case study was implemented to prove that safety visualization systems can promote a better understanding of safe behavior on construction sites. The results demonstrated that the system is effective in improving the identification of field safety risks 
amongst participants and consequently, in increasing their capacity of risk identification.

Perlman and Sacks (2014) investigated whether the ability of identifying hazards by civil engineering students and construction superintendents can be improved through VE learning. The results showed that the ability of hazard identification of both the students and construction superintendents is positively affected through the effective identification of a significant number of hazards. The results demonstrated also that construction superintendents are able to identify more risks than the students suggesting there is a potential link between the level of real world experience and the performance within the virtual environment.

Sacks et al. (2013) tested the construction safety knowledge of 66 participants prior to the training, immediately afterward, and 1 month later. The participants were divided into two groups: one half received traditional classroom training with visual aids; and the other half were trained using a 3D immersive VR power-wall. The results showed that the VR training provides advantage for specific site activities - e.g. stone cladding work and for cast-in-situ concrete work - but not for general site safety. It was also found that generally the VR training is more effective that the traditional classroom in maintaining the trainees' attention and concentration.

Teizer et al. (2013) argue that traditional teaching methods that are used to train and educate workers are the main source of education in most engineering industries in the USA and highlight the need for exploring new methods for safety leaning. They proposed a method of virtual reality training of iron workers in an indoor training center. The results showed that unsafe practices in VE can be easily detected and can provide an assessment of the effectiveness of the training in VE.

Visser et al. (2012) presented a simulation and computer based training program that was designed to reduce the distractions of operators of heavy machinery (Visser et al. 2012). The program addressed the cognitive distraction - thinking about irrelevant information causes operators to miss environmental cues - that could compromise plant safety and provided corresponding distraction avoidance strategies. The results from a case study indicated that overall the simulator and computerbased training program successfully improve operator skills in distraction avoidance.

Wang et al. (2007) assessed the application of augmented reality in heavy construction equipment training. They outlined an approach for developing an AR system to train novice operators in a real worksite environment populated with virtual materials and instructions (Wang and Dunston 2007). Wang et al. (2015) proposed a BIM-based model to support fire safety management. The model encompassed four components which are evacuation assessment, escape route planning, safety education, and equipment maintenance (Wang et al. 2015). The results demonstrated that utilizing the BIM model in the assessment and planning for fire safety can effectively support safety management.

Xie et al. (2006) and Xie and Carr (2010) proposed a VR safety-training system for construction workers. The results indicated that such methods of training produce memorable and lasting experiences for trainees (Xie and Carr 2010; Xie et al. 2006).

Zhang et al. (2013 and 2015) investigated an approach for establishing, storing and re-utilizing construction safety information. They proposed and tested a prototype application of ontology-based job hazard analysis and visualization. The results showed that the construction safety ontology permits an effective review of safety understanding and can facilitate the automated safety planning for job hazard analysis. Subsequently, they explored the link between BIM and a construction safety ontology for the purpose of safety knowledge management. The ontology linked different knowledge domains together. The model is updated to visualize the corresponding hazards and their analysis, e.g. a limited or congested workspace in the building of masonry wall. The results highlighted that job based hazard analysis can be linked to BIM to enable an improved visualization and awareness of potential risks.

Zhou et al. (2013) assessed the use of 4D visualization in detecting the evolving safety risks throughout the lifecycle of an underground metro construction project. The $4 \mathrm{D}$ visualization was combined with mathematical equations that numerically analyze the data and risks. The results of the study suggested the use of real-time data tracking and visualization facilitates the detection of safety risks throughout the entire project. However, it was noted that construction sites - and consequently risks - continually evolve and it is challenging to address this inherent characteristic with the proposed system.

\section{Result analysis}

This section analyses the results according to their distribution across: the risk management process, the engineering sector addressed by the studies, and the countries where the study originated.

\section{Coverage of VE studies for the risk management process}

The risk management process is a designated and proven approach for eliminating or mitigating risks in the construction and engineering industry. Managing safety risks in the engineering industry requires the knowledge and skills in the implementation of all the phases of the risk management process. Studies into VE for safety learning and training should address the need of this process, and in particular the three core phases of: risk identification, risk evaluation, and risk response planning. 
Table 6 shows the mapping of the identified studies against the phases of the risk management process. The results show that the existing VE research for safety learning and training has strongly focused on the risk identification phase while the phases of risk evaluation, risk response planning, and risk monitoring and control received less attention. There is also a lack of studies spanning across more than one phase with the exception of two studies combining risk identification with risk evaluation and one study combining risk evaluation and risk monitoring and controlling. Remarkably, none of studies provided a virtual environment to train and educate participants on all phases of the risk management process.

\section{VE studies for safety learning by industry sector and country}

The analysis of the results across the different engineering sectors shows an unbalanced distribution. 82\% (23) and $10 \%$ (3) of all the identified studies were found for applications in the building and civil sectors (Table 7). This finding is understandable as it reflects the focus on consistently high level of accidents in the building and civil engineering industry. It can be also explained by the large amounts of building and civil engineering projects compared to other industrial construction projects, for example, chemical, and oil and gas. A very limited number of studies were found in these sectors despite the potential catastrophic impact of realizing risk in such sectors. There is also a dearth of studies in the mechanical or manufacturing industry. However, the improvement to the learning and training of participants were

Table 6 Distribution of studies across the risk management process

\begin{tabular}{|c|c|c|}
\hline Risk Identification & 16 & $\begin{array}{l}\text { Lin et al. (201 1), Carozza et al. (2013), } \\
\text { Dawood et al. (2014), Dickinson et al. } \\
\text { (2011), Hadikusumo and Rowlinson } \\
\text { (2002), Guo et al. (2012), Guo et al. } \\
\text { (2013), Greuter et al. (2012), Nazir et al. } \\
\text { (2013), Nickel et al. (2013), Park et al. } \\
\text { (2013), Perlman and Sacks (2014), Sacks } \\
\text { et al. (2013), Teizer et al. (2013), Xie et al. } \\
\text { (2006), Zhang et al. (2015) }\end{array}$ \\
\hline Risk Evaluation & 7 & $\begin{array}{l}\text { Dickinson et al. (2011), Goulding et al. } \\
\text { (2012), Li et al. (2012a), Li et al. (2012b), } \\
\text { Li et al. (2015), Xie and Carr (2010), } \\
\text { Nakai et al. (2014) }\end{array}$ \\
\hline Risk Response Planning & 1 & Wang et al. (2015) \\
\hline $\begin{array}{l}\text { Risk Identification + Risk } \\
\text { Response Planning }\end{array}$ & 1 & Zhang et al. (2013) \\
\hline $\begin{array}{l}\text { Risk Identification + Risk } \\
\text { Evaluation }\end{array}$ & 2 & $\begin{array}{l}\text { Dickinson et al. (2011), Zhou et al. } \\
\text { (2013) }\end{array}$ \\
\hline $\begin{array}{l}\text { Risk Monitoring and } \\
\text { Controlling }\end{array}$ & 1 & Visser et al. (2012) \\
\hline $\begin{array}{l}\text { Risk evaluation + Risk } \\
\text { Monitoring and Controlling }\end{array}$ & 1 & Li et al. (2015) \\
\hline
\end{tabular}

Table 7 Distribution of studies across the engineering sectors process

\begin{tabular}{llll}
\hline Construction & Civil & Chemical & Oil \& Gas \\
\hline 23 & 3 & 1 & 1 \\
\hline
\end{tabular}

found not only in construction but also in all other sectors. For example, Nakai (2014) found for the chemical sector that the use of a VE, developed by linking a virtual reality system to a dynamic plant simulator, is effective in improving the safety performance of participants and reducing preventable accidents (Nakai et al. 2014). Another study for the oil and gas sector found that virtual plant simulators that train workers before they start working in the plant helped to increase the safety skills of the participants. The observed personnel behaved calmer under high pressure situations and was able to analyze scenarios in a more focused and logical manner (Nazir et al. 2013).

The use of VE for safety training is spread across many countries with the highest number of studies being generated in the U.S. (39\%), followed by China (21\%) and the United Kingdom (14\%) (Table 8). It must be noted that multidisciplinary and multinational research projects may involve researchers from several countries.

\section{Discussion}

This section respectively identifies the common characteristics across the VE studies reviewed, discusses the key gaps that warrant further attention and directions in VE-related for safety.

\section{Common characteristics among all studies}

The analysis of the identified studies provided general findings about: (a) the adopted VE technologies for safety learning and education; (b) the impact on VE on learning and training outcomes; (c) the impact of VE on the learning and training process, and (d) the influence of the design of VE content on the outcome and the process of leaning and training. These areas of analysis are explained in the subsequent paragraphs:

First, several methods were used to develop the VE for safety leaning and training. These included: Building Information Modeling (BIM) (e.g., 3D visualization, object-based modelling with embedded safety rules, 4D modelling and visualization), serious games, virtual reality and augmented reality (e.g., using cave automatic virtual environments called CAVES, goggles, headsets).

Table 8 Distribution of studies across the country of origin

\begin{tabular}{lllllllll}
\hline Australia & China & Germany & Italy & Japan & Korea & Taiwan & UK & USA \\
\hline 2 & 6 & 1 & 1 & 1 & 1 & 1 & 3 & 11 \\
\hline
\end{tabular}


Second, research into VE for safety learning and training has demonstrated a positive effect on the ability of participants to identify hazards and provided an effective way for engaging learners. Examples of key contributions so far focused on: a direct link between the computer program simulations and an improved learning performance is suggested (Ricci et al. 1996). VE learning and training increase the learning performance of participants (Sacks et al. 2013). For example, in a virtual construction setting, training individuals on different safety techniques in a three-sided CAVE showed a relative improvement in hazard recognition compared to the control group (Perlman and Sacks 2014). A serious game to train participants to identify safety hazards contributed to improve the perception of hazards on site (Lin et al. 2011). VE for education has also the potential to develop the user's analytical and strategic skills and increase the ability of recollection (Mitchell and Savill-Smith 2004). Construction workers with daily access to visual plant operation were able to easily identify potential safety problems. Practicing their skills of operating equipment virtually before actually performing the same task in reality helped avoiding hazards (Guo et al. 2013). This outcome conforms to the findings in other sectors and disciplines such as aviation, health, government, and military, among many others. For example, in the health sector, VE provide an effective means for rehabilitation (Rego et al. 2011), improve the motor neuron responses and coordination of patients (Shin et al. 2014; Clarke et al. 2011), and increase patients' engagement for stroke rehabilitation (Burke et al. 2009).

Third, VE can also reduce the time it takes for a learner to become competent and operational in their field of work (Bachvarova et al. 2012). Serious games are generally recognized for their ability in providing an engaging and innovative medium for delivering training (Dickinson et al. 2011). The use of a serious game with multipleplayer options increase the participant engagement and consequently the lesson learned is greater and more lasting (Greuter et al. 2012). VE also offer the benefit of enabling the user to experience scenarios that would ordinarily be difficult to materialize in the real world due to time, cost, and safety barriers (Squire and Jenkins 2003).

Finally, several of the studies identified and highlighted the importance of the characteristics of the VE on the learning experience of participants. According to Xie and Carr (2010), the experience in the virtual environment is less attractive and can have a lower engagement rate if it is immovable and soundless. Other research states, VR/AR tools such as $3 \mathrm{D}$ glasses and goggles enhance the learning experience by offering a more realistic training environment (Nickel et al. 2013). The scenario-led training, where trainees within virtual environment interact with predefined options in discrete game sections is considered a limiting factor for the learning and training experience of participants and an alternative free roaming sandbox style game should be developed (Dawood et al. 2014).

\section{Gaps identified and future research}

A number of research gaps were identified and matched with suggestion for future research directions. Each is illustrated in a separate paragraph.

\section{Heightened focus on risk identification}

The results exposed that safety learning and training in $\mathrm{VE}$ is mostly focused on the risk identification phase followed by risk evaluation. For example, (Carozza et al. 2013; Cheng and Teizer 2013; Dawood et al. 2014; Guo et al. 2013; Li et al. 2015) have all designed VE to train construction workers to identify risks (i.e., hazard spotting). Risk response planning which is a critical phase in the risk management process is the least explored phase. This heightened focus on the risk identification phase can be justified from several perspectives that are related to: the general principles of risk management; the safety best practices and legislation; and the ease of implementation in VE:

- In risk management, the first phase of risk identification is considered a crucial phase for the avoidance or reduction of risks. The capability of identifying hazards is an essential skill for reducing the likelihood of human errors and the anticipation of adverse safety conditions that could result in incident. In the real world, research demonstrated that the safety experience is considered a contributing factor to assisting in hazard recognition (Karwowski 2006; Moran 2003). It is suggested that by improving hazard recognition and risk perception abilities, the overall site safety will improve (Sawacha et al. 1999).

- Best practices in safety focus also on risk avoidance strategies which require the preliminary risk identification. For example, the UK Health and Safety at Work Act 1974 dictates that a safe system of work is mandatory. It also specifically states that each employee has a duty of care to themselves and to others that surround them. The first stage or line of defense in the prevention of hazards on site to ensuring a safe system of work is to identify the potential risks.

- Ease of implementation of risk identification in VE design: the implementation of hazard spotting or risk identification in VE is the least challenging from a technical standpoint. The minimum requirement can be to design a virtual environment where safety learners roam - either according to pre-set paths or free roaming the environment - while identifying and spotting the hazard. The design with the free roaming option was adopted in Dawood et al. (Guo 
et al. 2012). However, this minimum requirementdesign occurs on the expense of limited level of interactivity between users and VE and subsequently limited engagement by the users with adverse effects on their learners' experience.

Although the above analysis provides an explanation or a justification of the current emphasis of VE studies on the risk identification phase, VE research shall endeavor to address all the risk management phases including risk evaluation, risk response planning, and risk controlling. Indeed, the remaining three risk management phases are crucial to the execution or site phase of construction and engineering projects where most of the risks occur. Moreover, it is important that VE studies holistically and concurrently address the entirety of the risk management process. For a fully safe and functioning site, all elements of risk management should be acknowledged and practiced (Dallas 2008). For example, the UK's Management of Health and Safety at Work Regulations 1999 state that an emergency response plan - aka. Risk response planning - needs to be in place for contacting the emergency services, warning the relevant people, and minimizing the damage once an event has occurred.

Addressing these phases in VE will require facing the technical challenges in the design of VE such as: increased interactions between users and VE; recording of users' actions within the VE; integration of data from real life construction site into the VE environment; assessment of the users' actions in real-time/near realtime; embedded feedback within the VE about the learning performance; and providing the option to deal with the consequences of safety incidents. For example, in the case of fire safety, a detailed risk response plan would be required to consider the potential catastrophic impact on workers, the public and property.

Several of the above areas are still in their infancy. For example, VE for risk monitoring and controlling requires the integration of real-time data from the execution site and the imposition of the corresponding dynamic and changing scenes into the VE. Li et al. (2015) implemented a time location technology and Unity3D-based data visualization technology to track construction resources (people, equipment, materials, etc.) and provide real-time feedback and post-event visualization analysis in a VE for safety training. The electronic tagging of participants was used to monitor for proximity to risks and the likelihood of occurrence. In an earlier study (Teizer et al. 2013), near miss risks were detected and visualized through the implementation of real-time tracking and monitoring of hazards that surround site workers. More studies in the area of risk monitoring and controlling are required and the learning from this phase should be conveyed to the earliest phase of risk identification for effective avoidance and management of risks.

\section{Relationships between user's prior safety experience and performance in VE}

The VE studies analyzed have not reached a final conclusion as to whether the initial level of safety knowledge and experience affect the learning outcomes within a VE. Results from an investigation done by Perlman and Sacks (2014) on hazard recognition highlighted that construction superintendents are better equipped to recognize site hazards in comparison to student participants in the same study.

A study (Dawood et al. 2014) suggested that prior safety knowledge does not affect learning outcomes in terms of hazard identification in virtual environments. However, this latter study did not include a comparison of the performance of learners between the virtual environment and the real world. On the other hand, Perlman and Sacks (2014) compared the ability of learners in identifying hazard between the virtual environment and the traditional project documents (drawings, schedules and photographs) and proved that ability of learners in spotting hazards is better in virtual environments.

Another study (Nickel et al. 2013) also proved that immersing the workforce in the virtual environment, without being placed in danger, increases the workers perception to risk once they are back in the real world. This can affect the overall project safety performance the ability of workers of identifying risks before they turn into dangerous occurrences which help the prevention of many accidents (Mathi and Galloway 2013). In education theory, the importance of prerequisite learning and knowledge prior to embarking on a new learning journey is well known. It is suggested that future VE research increasingly explores this notion although it may be challenging to define the 'prerequisite' concept for VE learning. However, an empirical approach experimenting with different learner groups and involving the use of control groups may still provide adequate insights.

\section{Safety learning within the VE and the human factors}

Human error is considered a key contributor to safety risks resulting in accidents, near misses and serious incidents. Human error was addressed in a very limited number of the studies identified. Typically several causes are associated with human error. Visser et al. (2012) argue that distraction is one of the key factors causing accidents in civil work excavation. They developed a virtual environment to target the "cognitive distraction" that cause operators to miss environmental cues, such as warning lights, leading to safety incidents. Abdelhamid and Everett (2000) suggest that human errors usually occur from either workers negligence or lack of 
attentiveness to their tasks. Addison et al. (2013); Addison and O'Hare (2008) argue that many accidents occur as the result of human factors associated with inadequate competencies. Personnel in engineering industry require a high level of competence and training in order to operate safely and avoid potentially fatal accidents (Anderson 2005). The studies analyzed in our systematic literature review focused on the competency/skills aspect - although competencies were not clearly defined - for addressing the issue of safety risks in the construction and engineering industry. More research into the role of VE in addressing other safety causes related to cognitive issues such as distraction are therefore encouraged. Indeed, VE has enabled benefits in reducing human errors in other sectors. For example, virtual simulation systems to address human error contributed to reduce the occurrence of serious incidents in the aviation sector (Palanque and Johnson 2004). Experience can be transposed from other specialized sectors such as the aviation industry into the engineering sector as human error is a recognized possibility and a critical risk in both industries.

To be able to identify and monitor cognitive aspects in safety learning and training, the design of VE will require more sophisticated approaches. One potential future avenue is the design of situational serious games that include stringent checks (Dignum et al. 2009). Other factors related to human errors are attributed to demographic aspects such the age distribution and labor market composition. For example, in countries like Japan the high rate of skilled workers retiring and being replaced by young inexperienced workers was associated with the higher accident rates (Bust et al. 2008). Countries with increasing or high percentage of migrant workers are at more risk of accidents due to initial communication barriers (Bust et al. 2008). Therefore, domain researchers in VE for safety learning in construction and engineering are instigated to investigate the effect of VE in reducing safety incidents associated with human (e.g., communication) and cognitive (e.g., distraction) factors. The design of recent research studies, such as (Teizer 2016; Hilfert et al. 2016; Teizer et al. 2017; Ben-Alon and Sacks 2017) - were published outside the timeframe of this review - are opening up new avenues for emerging VE learners in a personalized VE education and training.

\section{Distribution of VE studies across the construction and engineering sectors}

The identified studies revealed an unbalanced distribution across the different construction and engineering sectors with the majority of studies being conducted in the building sector. This is a reasonable finding as the construction industry is considered one of the riskiest sectors to work for in most countries. Construction workers are three times more likely to fall victim of a fatal accident and twice as likely to be injured in comparison to workers in other occupations (Bust et al. 2008). However, due to the ethical, social and economic burden that results from accidents, more studies are required into other-than-construction sectors. With regards to the unbalanced distribution of studies across countries and the dominance of the U.S. position, this research also identifies the need to increase research and development activities into VE for safety learning and training in other countries.

\section{VE for safety learning and the targeted users}

The safety learning groups in the construction and engineering industry include current practitioners (i.e. engineers, designers, managers, safety officers, and laborers and operators) and more importantly students - future practitioners - who are pursuing their construction and engineering education in colleges and universities. The identified studies have targeted the need of both learning groups. Studies that involved learners from academia included (Lin et al. 2011; Dawood et al. 2014; Dickinson et al. 2011; Greuter et al. 2012; Xie and Carr 2010) who investigated the impact of VE on the effectiveness of safety learning of students in tertiary education. Much of the remaining studies involved participants from the industry. However, with the exception of a very limited number of studies - (Perlman and Sacks 2014; Sacks et al. 2013) - no control groups were used to enable the comparison of safety performance between the learners in VE with learners using other approaches. Providing such evidence can encourage the adoption of VE for safety training in the engineering sector.

\section{Key elements to improve the adoption of VE learning}

Hilfert et al. (2016), Teizer et al. (2017), Ben-Alon and Sacks (2017), Carozza et al. (2014 and 2015), and Albert et al. (2014) note that the availability of mature VE processes and technology is a primary reason that impact both the effective practical applications of VE in both research and practical applications. According to the scholars, four elements are needed for VE to become impactful in research and practical applications. These elements - mentioned subsequently - were also confirmed by our review and analysis. Examples of these tests are illustrated in Fig. 3. The four elements include: (1) VE-enabled safety learning processes and the embedded use of technology must allow the creation and use of field realistic VE scenarios easily and quickly. VE technology has still some remarkable technical deficits in creating field-realistic environment, for example, the field-of-view of headset goggles is limited and could cause sickness to test persons as a result of orientation loss; (2) wearable or remote sensors must be able to 


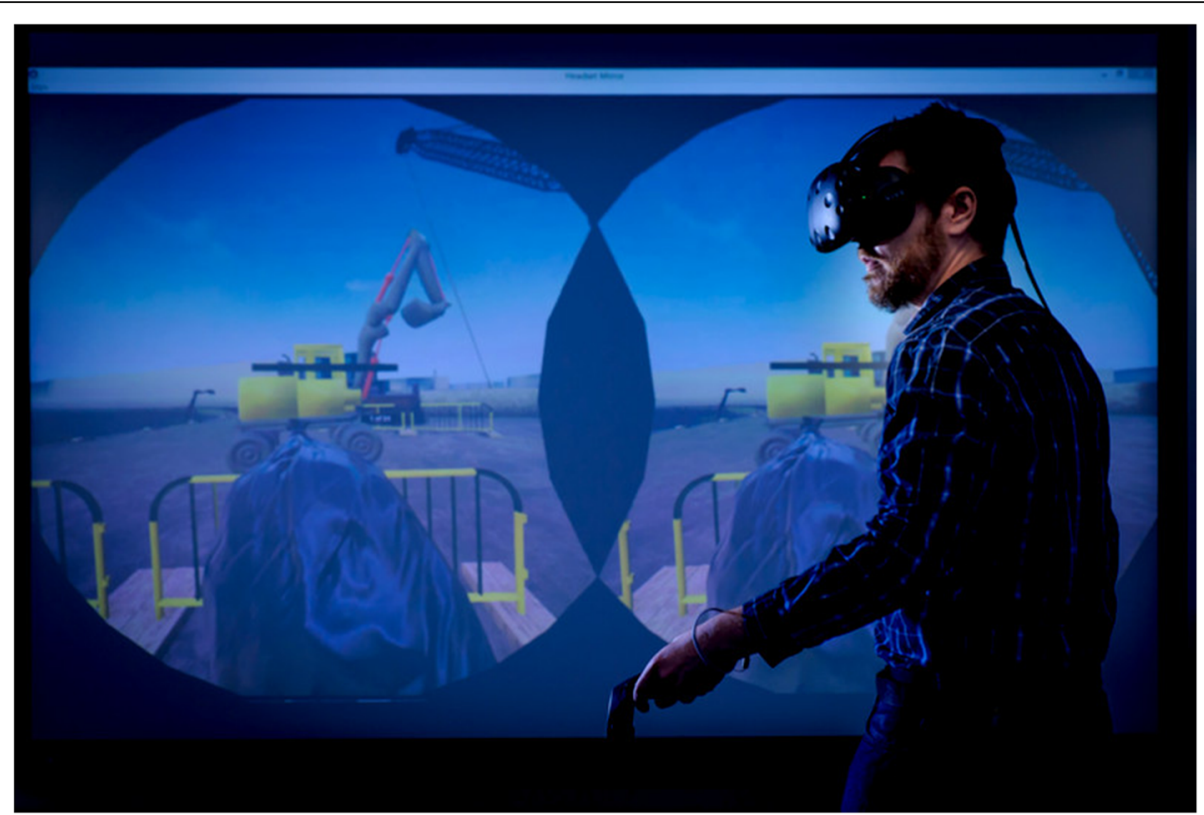

Fig. 3 Test bed environment for virtual reality in a construction safety training application (Hilfert et al. 2016)

record reliable data that are relevant to human behavior and convey such information into VE. The automatic analysis of human behavior - as demonstrated earlier is necessary to generate objective results, e.g. an objective measurement of the behavior of test persons while they are in VE worlds; (3) real-time computational algorithms must generate meaningful information that is geared towards empowering the test person's capability of managing all risk phases and improving over time; and (4) once the aforementioned steps have been successfully implemented, a rigid process needs to link all steps and embed them in existing and coherent risk management strategies.

\section{Conclusion}

Virtual environments (VE) are increasingly investigated for safety learning in the construction and engineering sectors. This study aimed to analyze and discuss existing studies, identify current gaps, and suggest avenues for future research. A systematic literature review was used as a primary research method and was combined with a gap analyses.

VE studies for safety learning were mainly focused on the risk identification phase of the risk management process. Positive impact of the ability of learners to spot hazards at this phase was identified across all the reviewed studies. However, as these identified risks require treatment in the subsequent risk management phases, researchers were instigated to address such phases including risk evaluation, risk response planning, and risk controlling in future VE studies. An adequate analysis of the causes for the concentration of existing studies on risk identification was presented and accompanied with suggestions for future research for safety learning.

The analyzed studies did not reach a consensus whether the initial real-world or gaming experience of learners affect their learning experience and performance within the VE. Limited evidence was also found from the comparison between the performances of learners in VE and those of learners using other approaches. Further studies that include control groups are therefore required to provide such evidence as it is deemed important for both the educational purpose of VE and their acceptance for safety training in the construction and engineering sector.

Very limited emphasis on human factors such as age, communication and cognitive distraction - all are considered key determinants for human errors in accidents, near misses, and other serious incidents - were identified. Insights that help considering such factors in future VE studies for safety learning were also proposed.

The current maturity and the ease of use of VE technology was identified as a key factor for advancing VE for safety learning into existing risk management processes and extending their use beyond the risk identification phase. Further suggestions related to the need for increasing investigations in sectors such as chemical, manufacturing, and oil and gas, and across countries were also highlighted.

The results provide a generalized understanding of state-of-the-art in research on VE safety learning within the construction and engineering sectors. The limitations are those typically inherent in the systematic literature review approach. Despite the attentive design of and 
adherence to the protocols of the systematic literature review, it is likely that some relevant papers were either not identified or unintentionally omitted during the review process. The focus on a few selected scientific databases (all of which are indexed and use digital object identifiers) may have further decreased the number of the results relevant to this study.

\section{Acknowledgements}

None.

\section{Funding}

The study did not receive any funding.

\section{Authors' contributions}

All authors contributed extensively to the work presented in this paper. MK and LB reviewed and analyzed the literature, developed the model, conducted the case study, analyzed the results, and drafted the manuscript. JT initiated, coordinated, and supervised the research process of this study and added content to and edited the manuscript. All authors read and approved the final manuscript.

\section{Competing interests}

The authors declare that they have no competing interests.

\section{Publisher's Note}

Springer Nature remains neutral with regard to jurisdictional claims in published maps and institutional affiliations.

\section{Author details}

'Department of Mechanical and Construction Engineering, Northumbria University, Newcastle, UK. ${ }^{2}$ Centre for Construction Innovation and Research, Teesside University, Middlesbrough, UK. ${ }^{3}$ Chair of Computing in Engineering, Ruhr-University Bochum, Bochum, Germany.

Received: 31 January 2017 Accepted: 14 August 2017

Published online: 31 August 2017

\section{References}

Abdelhamid, T. S., \& Everett, J. G. (2000). Identifying root causes of construction accidents. Journal of Construction Engineering and Management, 126, 52-60.

Addison, A., \& O'Hare, W. T. (2008). How can massive multi-user virtual environments and virtual role play enhance traditional teaching practice? In Relive 08 researching learning in virtual environments. Milton Keynes: The Open University.

Addison, A, O'Hare, WT, Kassem, M, Dawood, N (2013).The importance of engaging engineering and construction learners in virtual worlds and serious games. Proceedings of the 13th International Conference on Construction Applications of Virtual Reality, 30-31 October 2013 (pp. 448-457). London.

Albert, A., Hallowell, M. R., \& Kleiner, B. (2014). Emerging strategies for construction safety and health hazard recognition. Journal of Safety, Health, and Environmental Research, 10(2), 152-161.

Anderson, M. (2005). Behavioural safety and major accident hazards: magic bullet or shot in the dark? Process Safety and Environmental Protection, 83(2), 109-116.

Aveyard, H. (2010). Doing a literature review in health and social care: A practical guide. Maidenhead: Open University Press.

Bachvarova, Y., Bocconi, S., \& Popescu, S. (2012). Virtual worlds for serious applications (VS-GAMES'12): Measuring the effectiveness of learning with serious games in corporate training. Netherlands: Elsevier.

Ben-Alon, L., \& Sacks, R. (2017). Simulating the behavior of trade crews in construction using agents and building information modeling. Automation in Construction, 74, 12-27.

Boland, L. (2014). Doing a systematic review a student's guide. London: Sage.

Burdea, G. C., \& Coiffet, P. (2003). Virtual reality technology. New Jersey: Wiley.

Burke, J. W., McNeill, M. D. J., Charles, D. K., Morrow, P. J., Crosbie, J. H., \& McDonough, S. M. (2009). Serious games for upper limb rehabilitation following stroke. In Games and Virtual Worlds for Serious Applications, 2009 (pp. 103-110).
Bust, P. D., Gibb, A. G., \& Pink, S. (2008). Managing construction health and safety: Migrant workers and communicating safety messages. Safety Science, 46(4), $585-602$

Butler, G. (2014). Health and safety revision quide - the essential NEBOSH certificate revision. London: UK-HSE Ltd.

Carozza, I., Bosché, F., Abdel-Wahab, M. (2015). An immersive hybrid reality system for construction training. Proceedings of the 15th annual international conference on construction applications of virtual reality (pp. 1-10). Banff.

Carozza, L., Bosché, F., \& Abdel-Wahab, M. (2013). Image-based Localization for an Indoor VR/AR Construction Training System. International conference on Construction Applications of Virtual Reality (CONVR 2013). London, UK.

Carozza, L., Bosché, F., Abdel-Wahab, M. (2014). Robust 6-DOF immersive navigation using commodity hardware. Proceedings of the 20th ACM symposium on virtual reality software and technology (pp. 19-22). Edinburgh

Chen, S., \& Michael, D. (2005). Serious games: games that educate, train and inform. Thomson Course Technology: USA.

Cheng, T., \& Teizer, J. (2013). Real-time resource location data collection and visualization technology for construction safety and activity monitoring applications. Automation in Construction, 34, 3-15.

Clarke, C., Howard, R., Rossor, M., \& Shorvon, S. (2011). Neurology: a queen square textbook. Chichester: Wiley.

Dallas, M. (2008). Value and risk management: a guide to best practice. New York: Wiley.

Dawood, N., Miller, G., Patacas, J., \& Kassem, M. (2014). Construction health and safety training: The utilisation of $4 \mathrm{D}$ enabled serious games. ITCon, 19, 326-335.

Dickinson, J., Woodard, P., Canas, R., \& Ahamed, S. (2011). Game based trench safety education: Development and lessons learned. ITCon, 16, 119-134.

Dignum, F., Bradshaw, J., \& Doesburg, W. (2009). Agents for games and simulations: trends in techniques, concepts and design. London: Springer Science \& Business Media

Guo, L., Li, H., \& Li, V. (2013). VP-based safety Management in Large-Scale Construction Projects: A Conceptual Framework. Automation in Construction, $34,16-24$.

Goulding, J., Nadim, W., Petridis, P., \& Alshawi, M. (2012). Construction industry offsite production: A virtual reality interactive training environment prototype. Advanced Engineering Informatics, 26(1), 103-116.

Greuter, S., Tepe, S., Peterson, F., Boukamp, F., D'Amazing, K., Quigley, K., Van Der Waerden, R., Harris, T., Goschnick, T., \& Wakefield, R. (2012). Designing a game for occupational health and safety in the construction industry. In Proceedings of the $8^{\text {th }}$ Australasian Conference on Interactive Entertainment.

Guo, H. L., Li, H., Chan, G., \& Skitmore, M. (2012). Using game technologies to improve the safety of construction plant operations. Accident Analysis and Prevention, 48, 204-213.

Hadikusumo, B. H. W. \& Rowlinson, S. (2002). Integration of virtually real construction model and design-for-safety process database. Automation in Construction, 11(5), 501-510.

Hale, K., \& Stanney, K. (2014). Handbook of virtual environments: design, implementation, and applications (Second ed.). Florida: CRC Press.

Hamer, S., \& Collinson, G. (2005). Achieving EBP: A handbook for practitioners (2nd ed.). London: Elsevier Limited.

Hilfert, T., Teizer, J., \& König, M. (2016). First person virtual reality for evaluation and learning of construction site safety. In 33rd international symposium on automation and robotics in construction. Auburn.

HSE (2015b) A competent person. [Online] Available from: http://www.hse.gov. uk/involvement/competentperson.htm. Accessed in May 2016.

HSE, (2015a) Statistics on fatal injuries in the workplace in great Britain 2014. Available from: http://www.hse.gov.uk/statistics/pdf/fatalinjuries.pdf. Accessed in June 2016.

HSE, (2016). Statistics on fatal injuries in the workplace in Great Britain 2016, Health and Safety Executive statistics, Available from: http://www.hse.gov.uk/ statistics/. Accessed in June 2016

ISO, (2009). ISO 31000:2009- Risk management, Available from: http://www.iso. org/iso/home/standards/iso31000.htm. Accessed in June 2016.

Karwowski, W. (2006). International Encyclopaedia of ergonomics and human factors (Second ed.). Florida: CRC Press.

Kitchenham, B., \& Charters, S. (2007). Guidelines for performing systematic literature 1138 Q12 reviews in software engineering. Keele University and Durham University joint 1139 report, Durham, UK. 
Li, H., Huang, T., Kong, C. W., Guo, H. L., Baldwin, A., Chan, N., \& Wong, J. (2008). Integrating design and construction through virtual prototyping. Automation in Construction, 17(8), 915-922.

Li, H., Chan, G., \& Skitmore, M. (2012a). Visualizing safety assessment by integrating the use of game technology. Automation in Construction, 22, 498-505.

Li, H., Chan, G., \& Skitmore, M. (2012b). A Multiuser Virtual Safety Training System for Tower Crane Dismantlement. Computing and Civil Engineering, 26(5), 638-647.

Li, H., Lu, M., \& Chana, G. (2015). Proactive training system for safe and efficient precast installation. Automation in Construction, 49, 163-174.

Lin, K., Son, J. W., \& Rojas, E. M. (2011). A pilot study of a 3D game environment for construction safety education. ITcon, 16, 69-84.

Liu, B., Wang, Z., Song, G., \& Wu, G. (2010). Cognitive processing of traffic signs in immersive virtual reality environment: An ERP study. Neuroscience Letters, 485 43-48.

Mathi, T., \& Galloway, S. (2013). Steps to safety culture excellence. West Sussex: Wiley.

Mihelj, M., Novak, D., \& Beguš, S. (2013). Virtual reality technology and applications. London: Springer Science \& Business Media.

Mitchell, A. \& Savill-Smith, C. (2004). The use of computer and video games for learning: a review of the literature. Learning and skills development agency, Available on: www.LSDA.org.uk. Accessed in June 2015.

Moran, M. (2003). Construction safety handbook: a practical guide to OSHA compliance and injury prevention. Maryland: Government Institutes.

Nakai, A., Kaihata, Y., \& Suzuk, K. (2014). The experience-based safety training system using VR technology for chemical plant. International Journal of Advanced Computer Science and Applications, 5(11), 63-69.

Navarro. (2012). Modelling and simulation in engineering. International Journal of Multiphase Flow., 63(12), 11-22.

Nazir, S., Colombo, S., \& Manca, D. (2013). Minimizing the risk in the process industry by using a plant simulator: a novel approach. Chemical Engineering Transactions, 32, 109-114

Nickel, P., Lungfiel, A., \& Nischalke-Fehn, G. (2013). A virtual reality pilot study towards elevating work platform safety and usability in accident prevention. Safety Science Monitor, 17(2), 10-17

OSHA, (2017). Worker fatalities reported to federal and state OSHA: the construction industry, Available from: https://www.osha.gov/ StopFallsStandDown/index.html. Accessed in Feb 2017.

Palanque, P., \& Johnson, C. (2004). Human error, safety and systems development. In IFIP 18th world computer congress TC13 / WG13.5 7th working conference on human error, safety and systems development, 22-27 august 2004. Toulouse: Kluwer Academic Publishers.

Park, S. H., \& Kim, H. J. (2013). A framework for construction safety management and visualization system. Automation in Construction, 33, 95-103.

Perlman, A., \& Sacks, R. (2014). Hazard recognition and risk perception in construction. Automation in Construction, 64, 22-31.

Petticrew, M., \& Roberts, H. (2008). Systematic reviews in the social sciences: a practical guide. Paris: Wiley.

Rego, P. A., Moreira, P. M., \& Reis, L. P. (2011). Natural user interfaces in serious games for rehabilitation: A prototype and playability study. IEEE Transaction on Neural Systems and Rehabilitation Engineering, 2011, 1-4.

Ricci, K., Salas, E., \& Cannon-Bowers, J. A. (1996). Do computer-based games facilitate knowledge acquisition and retention? Military Psychology, 8(4), 295-307.

Sacks, R., Perlman, A., \& Barak, R. (2013). Construction safety training using immersive virtual reality. Construction Management and Economics, 31(9), 1005-1017

Sawacha, E., Naoum, S., \& Fong, D. (1999). Factors affecting safety performance on construction sites. International Journal of Project Management, 17(5), 309-315.

Sawyer, L., \& Rejeski, M. (2002). Improving public policy through game-based learning and simulation. Washington DC: Woodrow Wilson international Centre for scholars.

Shin, J.-H., Ryu, H., \& Jang, S. H. (2014). A task-specific interactive game-based virtual reality rehabilitation system for patients with stroke: a usability test and two clinical experiments. Journal of Neuro Engineering and Rehabilitation, 11, 32. doi:https://doi.org/10.1186/1743-0003-11-32.

Squire, K., \& Jenkins, H. (2003). Harnessing the power of games in education. Insight, 3(1), 5-33.

State Administration for Work Safety (2013). 2013 Annual Report, [online] Available from: http://www.chinasafety.gov.cn/. Accessed in July 2016.

Succar, B., \& Kassem, M. (2015). Macro-BIM adoption: Conceptual structures. Automation in Construction, 57, 64-79.
Teizer, J. (2016). Right-time vs. real-time pro-active construction safety and health system architecture. Construction Innovation: Information, Process, Management, Emerald, 16(3), 253-280 http://doi.org/10.1108/Cl-10-2015-0049.

Teizer, J., Melzner, J. (2015). Building Information Modeling-Technologische Grundlagen und industrielle Anwendungen: BIM im präventiven Arbeits-und Gesundheitsschutz, (Hrsg.) Borrmann, A., König, M., Beetz, J., Koch, C., Reihe VDI-Buch, Springer Verlag, ISBN 978-3-658-05605-6, 305-320, DOl https://doi. org/10.1007/978-3-658-05606-3_19.

Teizer, J., Cheng, T., \& Fang, Y. (2013). Location tracking and data visualization technology to advance construction ironworkers' education and training in safety and productivity. Automation in Construction, 35, 53-68.

Teizer, J., Green, A., Hilfert, T., Perschewski, M., \& König, M. (2017). Mobile point cloud assessment for trench safety audits. In 34th international symposium on automation and robotics in construction. Taipei.

Visser, T., Tichon, J., \& Diver, P. (2012). Reducing the dangers of operator distraction through simulation training. Dublin: SimTecT.

Wang, S., Wang, W., Wang, K., \& Shih, S. (2015). Applying building information modeling to support fire safety management. Automation in Construction, 59, $158-167$.

Wang, X., \& Dunston, P. S. (2007). Design, strategies, and issues towards an augmented reality-based construction training platform. Information technology in construction, international council for research and innovation. Building and Construction, 12(8), 363-380.

Watkins, R., Leigh, D., Foshay, R., \& Kaufman, R. (1998). Kirkpatrick plus: evaluation and continuous improvement with a community focus. Educational Technology Research \& Development, 46(4), 428-497.

Xie, H. and Carr, J. (2010). Ultrasonic sensor and 4D virtual reality simulation 1238 environment for safety training. Proceedings of the international conference on 1239 computing in civil and building engineering. Nottingham University press, Nottingham, UK.

Xie, H., Tudoreanu, E., \& Shi, W. (2006). Development of a virtual reality safetytraining system for construction workers. In Proceedings of the 6th international conference on construction applications of virtual reality (COVR2006) (pp. 3-4)

Zhang, J., Teizer, J. K. L., Eastman, C., \& Venugopal, M. (2013). Building information modelling (BIM) and safety: automatic safety checking of construction models and schedules. Automation in Construction, 29, 183-195.

Zhang, R., Zhang, Z., Liu, J., \& Zhang, S. (2014). The latest fundamental advances in the state of the art and practice of logistics, informatics, service operations and service science. In LISS 2013: Proceedings of 3rd international conference on logistics, informatics and service science. London: Springer.

Zhang, S., Boukamp, F., \& Teizer, J. (2015). Ontology-based semantic modeling of construction safety knowledge: towards automated safety planning for job hazard analysis (JHA). Automation in Construction, 52, 29-41.

Zhou, L., Ding, Y., \& Chen, L. J. (2013). Application of 4D visualization technology for safety management in metro construction. Automation in Construction, $34,25-36$.

\section{Submit your manuscript to a SpringerOpen ${ }^{\mathcal{O}}$ journal and benefit from:}

- Convenient online submission

- Rigorous peer review

- Open access: articles freely available online

- High visibility within the field

- Retaining the copyright to your article

Submit your next manuscript at springeropen.com 